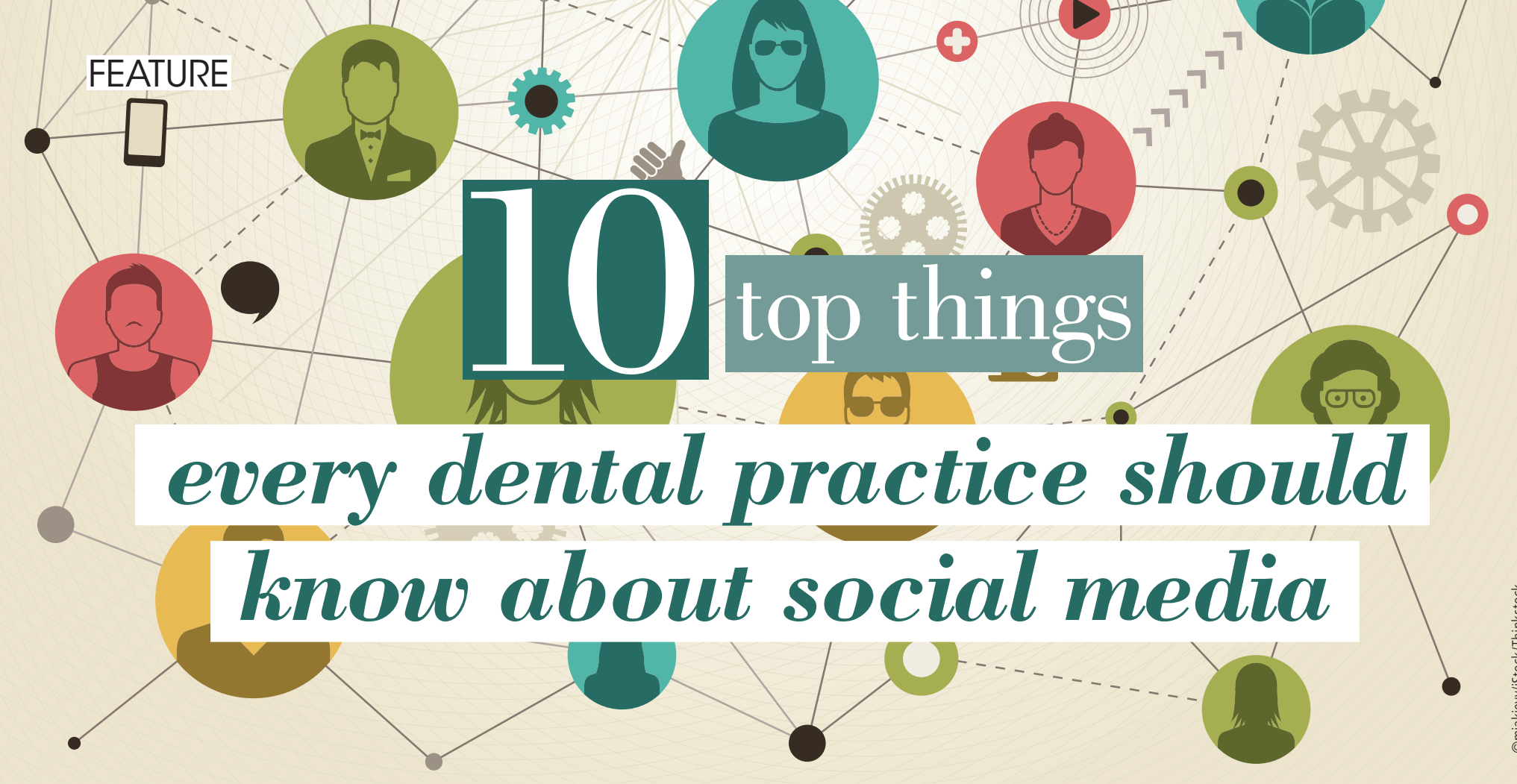

Ten top tips from Gemma Breeze, a dental nurse/marketing manager at Smile Essential in Leicester. Gemma has been at her practice since 2008 and keeps the practice's blog and social media pages up to date.

1 What's the point - will I get patients?

Ok so you more than likely won't be able to track tons of phone calls from social media but posting regularly can help drive potential patients through to your website and improve how high you rank on a Google search.

Social media works amazingly well for cementing the bonds in existing patient relationships. It can be hard to shake off the dark dentist image of yesteryear; connecting with patients in a twenty-first century way shows that dentistry has moved out of the dark ages.

2 It's time to step onto your own stage

When was the last time you posted a personal status or uploaded a photo? Before you plan to start posting on your dental practice's Facebook page it can help to share the odd status or post a pic of something of interest on your own Facebook account.

Facebook didn't come naturally to me and before I would launch a campaign I used to try and improve my social confidence by sharing pictures of my family or events and I found when the likes started to tot up so too did my confidence.

It's important to be your authentic self on social media but remember it is classed as a public domain, so aim to be personal but professional.

3 Silence can be deadly Don't be a silent snooper! We're all guilty of looking and not liking or commenting but being social is a two way transaction. So if you like it give a thumbs up; after a week of doing this stretch yourself a little further and write a comment.

This applies to both your personal and dental practice accounts. Following other dental organisations such as the BDJ, BDHF,

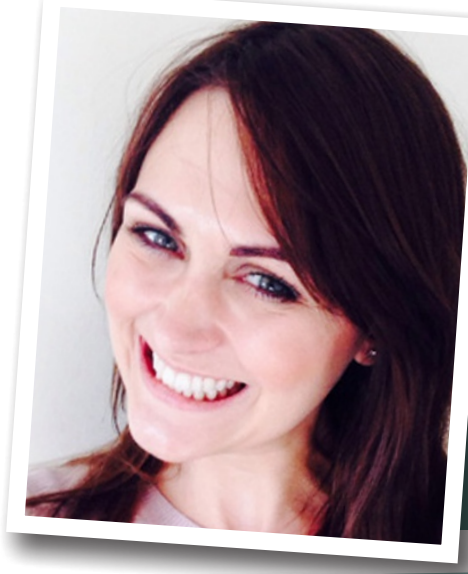

'IT'S IMPORTANT TO BE YOUR AUTHENTIC SELF ON SOCIAL MEDIA, SO AIM TO BE PERSONAL BUT PROFESSIONAL.

Colgate, BDA and other dental organisations will help to keep you in the know and help that organisation to keep the information coming your way. Interact regularly and you'll get noticed and they could start interacting with your stuff!

4 Facebook is not the social world

I'll be honest and admit I hated Twitter- who used it, why would they use it, it's too complicated, I can't keep up. When I actually took some time and learned how to do Twitter, it brought us in a lucrative patient. He recommended other patients and raved about us on Twitter and it was so easy!

So once you're comfortable using Facebook spend some time looking at other successful dental practices on Twitter. Already mastered these? Lucky you! There are so many to try and you might be surprised that it really works for you. You could try Instagram, Pinterest or try and help your Google ranking with Google+ posts. 


\section{Keeping it real}

Think about what people like to see when they flick through social media. Reminding people to brush twice daily for two minutes with a fluoride toothpaste is important in surgery and perhaps during a dental campaign or oral health month but it's unlikely to be a social media hit with your patients if it's otherwise.

People love to see a bit of personality and information that's only really shared on social media whether that be a weird dental fact, a look behind the scenes at your practice or seeing your practice in a new light because you've shared a picture of yourself with the latest gadget, a team award or even being naughty treating yourself to a chocolate biscuit that a patient brought in for you.

We all love finding out more about people and creating mini profiles of all the dental team with the odd fun questions thrown in; this can strike a chord with your patients. Too often practices seem to separate their online and practice activities. This will help the team to feel connected. It will also have the added benefit of your team being online and offline branding being kept in sync.

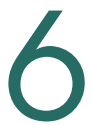

\section{Book yourself} an appointment

Finding the time to post to social media is tricky- Mrs Jones has lost a crown, Timmy has broken his tooth falling from his bike and Mr Smith forgot he had a mouth full of meta and treated himself to a toffee with a surprise lost filling! Now to write up the notes for the day and $\mathrm{hmmm}$ let's do a fun engaging post to Facebook.

Facebook easily lets you schedule your posts months in advance, so try and find an hour somewhere in the week when you're relaxed and plan 2-3 posts for that week. Perhaps a photo of the team on a course or work outing, a tip for fresh breath and a patient testimonial. Just remember to schedule them at a good and convenient time. I find $1 \mathrm{pm}$ and $6 \mathrm{pm}$ work well because this is when people have a break from work and if someone comments I will be able to respond back quickly.

There are also websites which allow you to post Facebook and other social media sites such as Twitter in advance. Once you're a.

on social media Advertising your social media sites in the practice is a good start, incentivising it with a simple competition is better but by far the best way is to ask them directly.

Talk to your team about how to ask and acknowledge when someone they have asked has taken action.

'Joan we are currently growing our Facebook page and would love you to connect with us on there I'll send you a link or you can search us INSERT PRACTICE NAME: Or 'John are you on Facebook? Yes. Great we love connecting with patients and would appreciate it next time you're online to give us a like.'

Keep trying different wording on patients until you find something your whole team feel comfortable saying and is working to get your patients following you.

\section{8} Don't go it alone

The saying it takes a village to raise a child can be heard as it takes a whole dental team to make your dental practice a success. This is true for the social media part as well. It can be difficult constantly coming up with ideas or an event that has happened at work when you weren't there. Encourage everyone to share ideas and if something happens in your absence to take and send you a picture.

If you have someone creative and trustworthy in your team who is a brand advocate for your practice then why not let them do some of the social media. You could let them do all or just part of it. Be clear what the guidelines are and work together for the first few weeks to ensure the message you give is what you really want.

Sometimes it's necessary to get a little extra help and if you've come to a dead end or are finding it stressful don't give up! There are lots of social media workshops and dental companies providing personalised analysis and training. Investing a little could help a lot.

\section{A picture says a thousand words \\ I would go as far as saying at least $70 \%$} of the time you should be sharing a picture with your social media posts.

By sharing a picture with your social media posts you will significantly increase the chance of people engaging with it. This is for two reasons: firstly a picture will of course make your post stand out more and secondly social media sites such as Facebook know that its audiences prefer to see imagery so it will favour showing your post.

When I said share a picture at least $70 \%$ of the time what I really meant was $100 \%$ time on Facebook, Instagram, Google+ and Pinterest and $70 \%$ on Twitter.

Don't let the 160 word capacity of Twitter fool you. The small capacity of space on Twitter can mean that it has a tendency to be text heavy. A Twitter audience wants news, information, facts and it wants them fast. So try and incorporate some imagery in Twitter, it could be picture, a video or the fun use of an emoji or two.

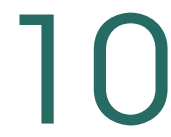

\section{GDC: the rules \\ This may be the final point and it's one that lots of dental} professionals agonise over and ultimately puts dental professionals off social media- but it shouldn't. I find the General Dental Council (GDC) rules are fairly straightforward and easy to follow- it's the not knowing what's-what that's most worrying.

The GDC standards set out the standards of conduct, performance and ethics that govern you as a dental professional and this includes social media.

I recommend to read section 9 in particular in regards to social media 'Make sure your personal behaviour maintains patients' confidence in you and the dental profession'. Also the additional guidance sheet on using social media (which mainly refers to your own personal social media) and the guidance on advertising (which apply more so to your dental practice's social media) is very important.

All of the sections and guidance sheets I've recommended are short and easy to understand. I'd recommend printing them and having a read; it should only take about 30 minutes to read the lot and you can highlight any areas you need to pay particular attention to. 